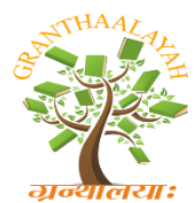

\author{
INTERNATIONAL JOURNAL OF R
GRANTHAALAYAH
}

DOI: https://doi.org/10.29121/granthaalayah.v7.i10.2019.397

Science

\title{
THE EVALUATION OF THE EFFECTS OF LYMPH NODE REVEALING SOLUTION ON AXILLARY DISSECTION MATERIAL
}

\author{
Tangul Bulut *1, Ayse Arducoglu Merter ${ }^{2}$, Betul Celik ${ }^{1}$ \\ ${ }^{*}$ MD, Department of Pathology, University of Health Science, Antalya Training and Research \\ Hospital, Antalya, Turkey \\ ${ }^{1}$ Associate Professor, Department of Pathology, University of Health Science, Antalya Training \\ and Research Hospital, Antalya, Turkey \\ ${ }^{2}$ MD, Department of General Surgery, University of Health Science, Antalya Training and \\ Research Hospital, Antalya, Turkey
}

\begin{abstract}
Objective: Nodal status is still the most important independent prognostic factor in breast cancer. In this study, we aimed to investigate the effect of lymph node revealing solution (LNRS) on the number and diameter of removed lymph nodes and nodal staging.

Study Design: Consecutive 150 patients, diagnosed breast carcinoma, were included in the study. After excising the lymph nodes by the traditional method, remaining axillary tissue was immersed in LNRS for 6-12 hours. lymph nodes, which stood out as white chalky nodules, were excised and processed as usual.

Results: An increase of 5.80 (32.03\%) in the number of lymph nodes per case was observed, which was statistically significant. The diameters of the lymph nodes removed with LNRS were smaller compared to the classical method, and this was statistically significant as well. Furthermore, the LINES changed nodal stage of the disease in five of the studied cases.

Conclusions: LNRS increases the number of lymph nodes that are removed and detects smaller lymph nodes. It may be an alternative method in cases with removed lymph nodes are critical number or under. Thus, accurate nodal staging and prognostic information will be obtained by using LNRS and more accurate treatment management will be provided.
\end{abstract}

Keywords: Lymph Node Revealing Solution; LNRS; Nodal Staging; Prognosis; Dissection Material.

Cite This Article: Tangul Bulut, Ayse Arducoglu Merter, and Betul Celik. (2019). "THE EVALUATION OF THE EFFECTS OF LYMPH NODE REVEALING SOLUTION ON AXILLARY DISSECTION MATERIAL." International Journal of Research Granthaalayah, 7(10), 269-279. https://doi.org/10.29121/granthaalayah.v7.i10.2019.397. 


\section{Introduction}

After lung cancer, breast cancer is the most commonly observed malignant tumor and that has the highest mortality among women worldwide (1). Tumor size, histological type, histological grade, hormone receptors, and human epidermal growth factor receptor 2 positivity are important parameters that determine the prognosis of patients with breast cancer (2-4). Except for haematogenous dissemination observed in a small portion of breast cancer, the axillary lymph nodes are the first metastatic site and the nodal status is still the most important independent prognostic factor $(5,6)$.

Breast carcinoma staging (pTNM) is made by considering tumor size and spread, nodal status and distant metastasis. Nodal staging is based on both the number of metastatic lymph nodes and the metastasis diameter (7). While 5-year overall survival was reported as 93\% in node-negative patients, this rate could be decrease as low as $50 \%$ in node-positive patients $(8,9)$. Furthermore, only patients with 1-3 node-positive cases have better prognosis compared to those with 4 or higher node-positive patients $(8,9)$.

After overnight fixation with $10 \%$ buffered formalin, lymph nodes are removed from axillary fat tissue in routine practice. In this study, we aimed to investigate the effect of fixation of remaining axillary tissue with lymph node revealing solution (LNRS) on the number of removed lymph nodes and diameter and, also the effect on nodal staging.

\section{Materials and Methods}

After obtaining the ethics committee's approval, patients who had undergone surgery for invasive breast carcinoma and who had axillary lymph node dissection (ALND) performed together with modified simple mastectomy, quadrantectomy, and segmental mastectomy at the Ankara Oncology Training and Research Hospital tertiary healthcare center were included in the study. This prospective study comprised consecutive patients that were classified into the 6-hour, 9-hour and 12-hour groups, with each group comprising 50 patients (10). ALND material was divided into three groups; lymph nodes exterior and inferior sides of the pectoralis minor muscle (Level I, low group), lymph nodes on posterior sides of pectoralis minor muscle (Level II, middle group) and lymph nodes between on the medial sides of pectoralis minor muscle and inferior sides of the clavicle (Level III, upper group) by the surgeon. As required by the routine works of the pathology laboratory, these lymph nodes were removed from axillary fat tissue by different pathologists after they were immersed in $10 \%$ buffered formalin fixation (classical method) overnight (Fig. 1A). The remaining axillary tissue was immersed for 6-12 hours in a volume of LNRS three times greater than that of the material. The LNRS was prepared immediately before use, and comprised $65 \mathrm{ml}$ of $95 \%$ ethanol, $20 \mathrm{ml}$ of diethyl ether, $5 \mathrm{ml}$ of glacial acetic acid, and $10 \mathrm{ml}$ of buffered formalin, for a total of $100 \mathrm{ml}$. The material was washed with large amounts of tap water after fixation and then cut into 2-mm thick sections; the lymph nodes were again removed by a single researcher after excluding the lymph nodes that had already been sampled in the first retrieval. The lymph nodes were embedded in paraffin blocks, sectioned, and stained with H\&E (Hematoxylin and Eosin). 
Lymph node diameters were measured in the H\&E-stained slides that were prepared after formalin and LNRS fixations. To evaluate the effect of LNRS fixation on immunohistochemical stain, the PanCK, CD68, EMA, and LCA stains were applied on a few lymph nodes (Fig. 2C, 2D). Histological classification of both primary breast carcinoma and axillary metastases were performed according to the classification of World Health Organization.

The number and diameters of lymph nodes removed using both the classical method and LNRS method, as well as the presence or absence of metastases were recorded. Additional lymph nodes obtained using the LNRS were added to those obtained using the formalin solution, and the relation between the number and diameters of lymph nodes were examined using both methods. The results were assessed using the paired t-test, chi square test, Wilcoxon test and Kendall's Tau B method. $P$ values $<0.05$ were considered as statistically significant. The data obtained were examined using SPSS software version 11.5 (Chicago, USA, INC.).

\section{Results}

A total of 150 patients were included in the study, including 146 women and 4 men. The age distribution was 20 to 78 years, while the mean age was $51 \pm 12,09$. The clinical and pathological characteristics of these cases and the surgical methods used are summarized in Table 1.

In the macroscopic examination, it was observed that LNRS fixation resulted in the observation of firmer lymph nodes with a white chalk-like color on their cut surfaces compared with that observed using the formalin solution method (Fig. 1B). A 1-mm diameter lymph node that could not be detected in the axillary material using the classical method was easily identified using the LNRS method (Fig. 1C). In microscopic evaluation, it was observed that H\&E and immunohistochemical stains obtained after LNRS had the same characteristics as the slides obtained after the formalin fixation only, indicating that LNRS fixation did not affect pathological examination (Fig. 2).

In two patients whose lymph nodes were not detected using the classical method, the lymph nodes could not be identified using the LNRS method as well. Moreover, there were two patients in whom additional lymph nodes could not be detected using the LNRS method even though the lymph nodes could be found using the classical method. In total, there were four patients in whom the LNRS method was unable to detect lymph nodes (Table-4). These cases were excluded from the relevant parts of the statistical evaluation.

The total number of lymph nodes removed using the classical method was 2693, and the average number of lymph nodes per case was $17.95 \pm 7.74$. With an additional 869 lymph nodes $(32.3 \%)$ obtained after LNRS, the total number of lymph nodes obtained from axillary material increased to 3562 , and the average number of lymph nodes found per patient was $23.75 \pm 8.74$ (Table-2). Thus, an increase of $5.80(32.03 \%)$ in the number of lymph nodes per case was observed, which was statistically significant $(p<0,001$, Table-2). At three axillary levels, the diameters of the lymph nodes removed using LNRS were smaller than those retrieved using the classical method, and this was found to be statistically significant (Table-2). 
In our study, a total of 142 additional lymph nodes were removed after LNRS fixation in 19 patients that less than 10 lymph nodes were removed using the classical method (Table-3, 4). The total number of lymph nodes increased to 250 together with the additional lymph nodes that obtained through LNRS (Table-3, 4). In this group, the mean number of lymph nodes per patient was $7.47 \pm 1.5$ using the classical method and 13.15 \pm 4.2 using LNRS, and the difference between these two methods was statistically significant $(p<0.001$, Table-4). There was an increase in the number of positive nodes, whereas there was no statistically significant difference between the classical method and LNRS in the ratio of positive nodes/total nodes (\%) $(P>0.05$, Table-4). However, while the number of cases in which less than 10 lymph nodes were removed using the classical method was 19 , this number decreased to five using the LNRS method. This notable decrease was statistically significant ( $p<0.01$, Table-4).

Following fixation with LNRS on the 19 cases in which less than 10 lymph nodes were removed through the classical method, two of the eight patients had their stage progress from N0 to N1a, two from N1a to N2a and one from N2a to N3a. Thus, the nodal stage progressed in five of these 19 cases, which was statistically significant $(p<0.001$, Table-4).

Table 1: Distributions of cases according to age, gender, tumor size and Histopathological type and surgical procedure

\begin{tabular}{|c|c|c|c|}
\hline & & $\mathbf{n}$ & $\%$ \\
\hline & Female & 146 & 97.3 \\
\hline & Male & 4 & 2.7 \\
\hline \multirow[t]{4}{*}{ Age } & $35>$ & 11 & 7.3 \\
\hline & $35-45$ & 36 & 24 \\
\hline & $46-55$ & 43 & 258.7 \\
\hline & $55<$ & 60 & 40 \\
\hline \multirow[t]{3}{*}{$\begin{array}{l}\text { Surgical } \\
\text { procedure }\end{array}$} & $\begin{array}{ll}\text { Modified } & \text { Radical } \\
\text { Mastectomy } & \\
\end{array}$ & 135 & 90 \\
\hline & Segmental mastectomy & 12 & 8 \\
\hline & Quadrantectomy & 3 & 2 \\
\hline \multirow[t]{3}{*}{ Tumor size $(\mathrm{cm})$} & 2> & 46 & 30.7 \\
\hline & $2-5$ & 87 & 58 \\
\hline & $5<$ & 17 & 11.3 \\
\hline \multirow{2}{*}{$\begin{array}{l}\text { Histopathological } \\
\text { diagnosis }\end{array}$} & NST* & 131 & 87.3 \\
\hline & Others & 19 & 12.7 \\
\hline
\end{tabular}


Table 2: After formalin and LNRS fixations, Nodal status, the mean number and diameters of Lymph nodes in cases, and evaluation of LNRS fixation times

\begin{tabular}{|c|c|c|c|c|c|}
\hline & \multicolumn{2}{|c|}{ Formalin fixation } & \multicolumn{2}{|c|}{ LNRS fixation } & \multirow[b]{2}{*}{$P$} \\
\hline & $\mathrm{n}$ & $\%$ & $\mathrm{n}$ & $\%$ & \\
\hline Node negative cases & 63 & 42.6 & 95 & 65.1 & \\
\hline \multirow[t]{2}{*}{ Node positive cases } & 85 & 57.4 & 51 & 34.9 & \\
\hline & \multicolumn{2}{|c|}{ Mean \pm SD } & \multicolumn{2}{|c|}{ Mean \pm SD } & \\
\hline The number of lymph nodes & \multicolumn{2}{|c|}{$17.95 \pm 7.74$} & \multicolumn{2}{|c|}{$23.75 \pm 8.74$} & $<0.001$ \\
\hline \multicolumn{6}{|l|}{ The diameter of lymph nodes } \\
\hline Axilla Level I & \multicolumn{2}{|c|}{$0.24 \pm 0.15$} & \multicolumn{2}{|c|}{$0.15 \pm 0.11$} & $<0.001$ \\
\hline Axilla Level II & \multicolumn{2}{|c|}{$0.32 \pm 0.25$} & \multicolumn{2}{|c|}{$0.19 \pm 0.16$} & $<0.01$ \\
\hline Axilla Level III & \multicolumn{2}{|c|}{$0.29 \pm 0.17$} & \multicolumn{2}{|c|}{$0.21 \pm 0.15$} & $<0.001$ \\
\hline \multicolumn{6}{|l|}{ LNRS fixation time groups } \\
\hline 6 hours & \multicolumn{2}{|l|}{-} & \multicolumn{2}{|c|}{$5.70 \pm 4.61$} & \multirow{3}{*}{$>0,05$} \\
\hline 9 hours & \multicolumn{2}{|l|}{-} & \multicolumn{2}{|c|}{$5.83 \pm 3.56$} & \\
\hline 12 hours & \multicolumn{2}{|l|}{-} & \multicolumn{2}{|c|}{$5.86 \pm 3.52$} & \\
\hline
\end{tabular}

Table 3: Node-positive, total node, and nodal stage determined using the LNRS method in patients with less than 10 lymph nodes found using the classical method

\begin{tabular}{|c|c|c|c|c|c|c|}
\hline & \multicolumn{3}{|c|}{ Formalin fixation } & \multicolumn{3}{|c|}{ LNRS fixation } \\
\hline$n$ & $\begin{array}{l}\text { The number of } \\
\text { positive nodes }\end{array}$ & $\begin{array}{c}\text { Total number } \\
\text { of nodes }\end{array}$ & Stage & $\begin{array}{l}\text { The number of } \\
\text { positive nodes }\end{array}$ & $\begin{array}{c}\text { Total number } \\
\text { of nodes }\end{array}$ & Stage \\
\hline 1 & 1 & 8 & N1a & 0 & 1 & N1a \\
\hline 2 & 0 & 6 & N0 & 0 & 9 & N0 \\
\hline 3 & 4 & 4 & $\mathrm{~N} 2 \mathrm{a}$ & 4 & 4 & $\mathrm{~N} 2 \mathrm{a}$ \\
\hline 4 & 0 & 6 & N0 & 0 & 9 & N0 \\
\hline 5 & 8 & 9 & $\mathrm{~N} 2 \mathrm{a}$ & 4 & 4 & N3a* \\
\hline 6 & 1 & 8 & N1a & 0 & 4 & N1a \\
\hline 7 & 2 & 9 & $\mathrm{~N} 1 \mathrm{a}$ & 1 & 11 & N1a \\
\hline 8 & 0 & 9 & N0 & 1 & 8 & N1a* \\
\hline 9 & 0 & 8 & N0 & 0 & 8 & N0 \\
\hline 10 & 1 & 5 & $\mathrm{~N} 1 \mathrm{a}$ & 4 & 10 & $\mathrm{~N} 2 \mathrm{a}^{*}$ \\
\hline 11 & 0 & 9 & N0 & 2 & 10 & N1a* \\
\hline 12 & 1 & 6 & N1a & 0 & 0 & N1a \\
\hline 13 & 1 & 8 & N1a & 3 & 10 & $\mathrm{~N} 2 \mathrm{a}^{*}$ \\
\hline 14 & 0 & 8 & N0 & 0 & 1 & N0 \\
\hline 15 & 1 & 8 & N1a & 1 & 3 & N1a \\
\hline 16 & 0 & 8 & N0 & 0 & 8 & N0 \\
\hline 17 & 2 & 8 & N1a & 0 & 6 & N1a \\
\hline 18 & 3 & 9 & N1a & 0 & 2 & N1a \\
\hline 19 & 0 & 6 & N0 & 0 & 0 & N0 \\
\hline
\end{tabular}


Table 4: Lymph nodes characteristics and changes in stage after LNRS in patients with less than 10 lymph nodes found using the classical method

\begin{tabular}{|c|c|c|c|c|c|c|c|c|c|c|c|c|}
\hline & \multicolumn{5}{|c|}{ Formalin fixation } & \multicolumn{5}{|c|}{ LNRS fixation } & & \\
\hline & \multicolumn{5}{|c|}{ Mean \pm SD } & \multicolumn{5}{|c|}{ Mean \pm SD } & \multicolumn{2}{|l|}{$p$} \\
\hline $\begin{array}{l}\text { Total number } \\
\text { of removed } \\
\text { lymph nodes }\end{array}$ & \multicolumn{5}{|l|}{142} & \multicolumn{5}{|c|}{250} & \multicolumn{2}{|l|}{---} \\
\hline $\begin{array}{l}\text { Mean Lymph } \\
\text { node number }\end{array}$ & \multicolumn{5}{|l|}{$7.47 \pm 1.5$} & \multicolumn{5}{|c|}{$13.15 \pm 4.2$} & \multicolumn{2}{|l|}{$<0.001 *$} \\
\hline $\begin{array}{l}\text { Number of } \\
\text { cases with no } \\
\text { lymph node }\end{array}$ & \multicolumn{5}{|l|}{2} & \multicolumn{5}{|l|}{4} & \multicolumn{2}{|l|}{---} \\
\hline $\begin{array}{l}\text { The number of } \\
\text { positive nodes }\end{array}$ & \multicolumn{5}{|l|}{$25(17,6)$} & \multicolumn{5}{|c|}{$20(8,0)$} & \multicolumn{2}{|l|}{$>0,05^{*}$} \\
\hline $\begin{array}{l}\text { Positive nodes } \\
\text { /Total nodes ( } \\
\%)\end{array}$ & \multicolumn{5}{|l|}{$12,5(0-100)$} & \multicolumn{5}{|c|}{$11,11(0-100)$} & \multicolumn{2}{|l|}{$>0.05^{\mp}$} \\
\hline $\begin{array}{l}\text { The number of } \\
\text { cases with } \\
\text { removed less } \\
\text { than } 10 \text { lymph } \\
\text { nodes }\end{array}$ & \multicolumn{5}{|l|}{$19(12,5)$} & \multicolumn{5}{|c|}{$5(3,3)$} & \multicolumn{2}{|l|}{$<0,01^{\ddagger}$} \\
\hline \multirow{7}{*}{$\begin{array}{l}\text { Nodal stage } \\
\text { change }\end{array}$} & \multirow[t]{3}{*}{ Formalin } & \multicolumn{8}{|c|}{ LNRS } & \multirow[t]{3}{*}{ Total } & \multirow{3}{*}{$\begin{array}{l}\text { Kendall's } \\
\text { Tau B } \\
\text { coefficient }\end{array}$} & \multirow[t]{3}{*}{$P$} \\
\hline & & \multicolumn{2}{|c|}{ No } & \multicolumn{2}{|c|}{ N1a } & \multicolumn{2}{|c|}{$\mathrm{N} 2 \mathrm{a}$} & \multicolumn{2}{|c|}{ N3a } & & & \\
\hline & & $\mathrm{N}$ & $\%$ & $\mathrm{~N}$ & $\%$ & $\mathrm{~N}$ & $\%$ & $\mathrm{~N}$ & $\%$ & & & \\
\hline & N0 & 6 & 75,0 & 2 & 25,0 & 0 & 0,0 & 0 & 0,0 & 8 & 0,808 & 0,001 \\
\hline & $\mathrm{N} 1 \mathrm{a}$ & 0 & 0,0 & 7 & 77,8 & 2 & 22,2 & 0 & 0,0 & 9 & & \\
\hline & $\mathrm{N} 2 \mathrm{a}$ & 0 & 0,0 & 0 & 0,0 & 1 & 50,0 & 1 & 50,0 & 2 & & \\
\hline & Total & 6 & & 9 & & 3 & & 1 & & & & \\
\hline
\end{tabular}

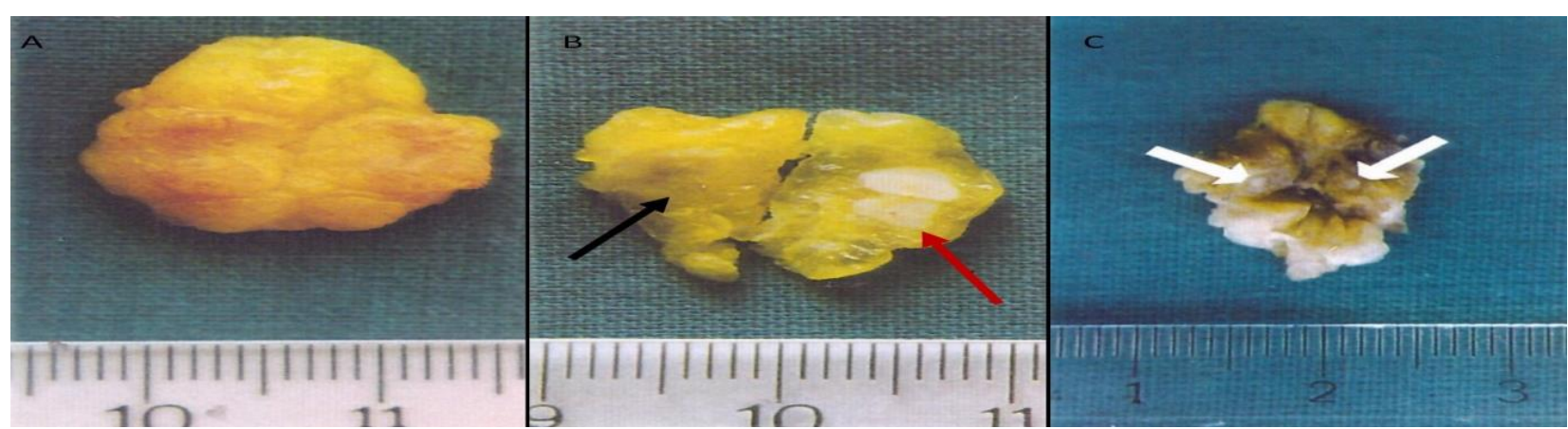

Figure 1: 1A: Appearance of a dissected lymph node before formalin and LNRS fixation.1B: Appearance of a lymph node after formalin fixation (black arrow) and the whiter, chalk-like appearance of a lymph node after LNRS fixation (red arrow), facilitating easier visualization compared with formalin fixation. 1C: Appearance of white-colored lymph nodes of $1 \mathrm{~mm}$ that were overlooked after formalin fixation but were detected in the axillary fatty tissue (white arrows) following LNRS 


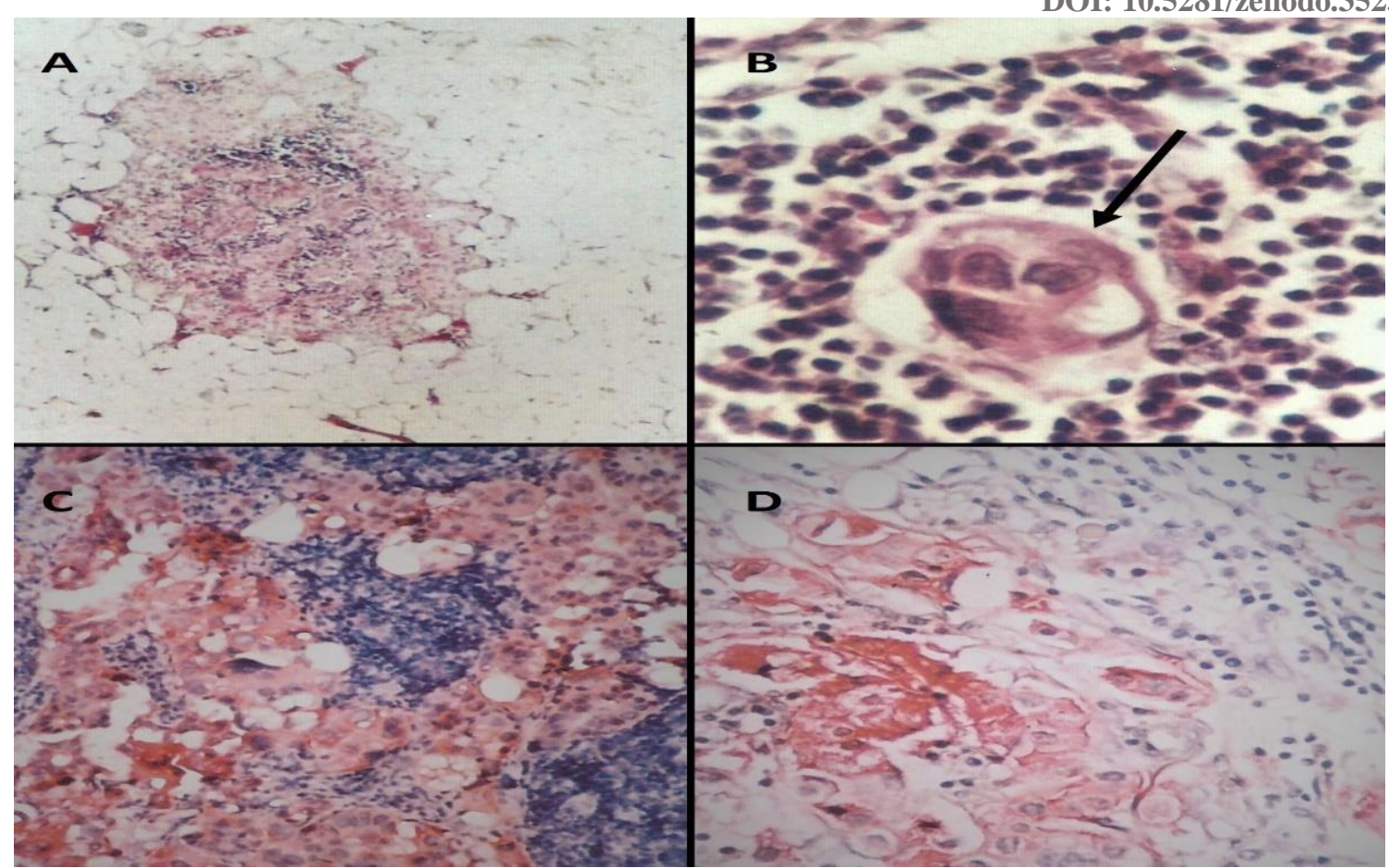

Figure 2: 2A: Breast carcinoma metastases observed in smaller sized lymph nodes in fat tissue, (H\&Ex40), 2B: Epithelial tumor island inside lymphoid tissue (black arrow) (H\&Ex400), 2C:

Positive staining of breast carcinoma metastasis in Lymph node with PanCK (x100), 2D:

Positive staining of breast carcinoma metastasis in Lymph node with EMA (x200)

\section{Discussion}

Breast carcinoma has been recognized as a major public health problem worldwide $(1,11)$. In previous studies, while recurrence, disease-free survival, and general survival rates decreased in an inversely proportional manner compared with the increase in the number of positive lymph nodes, they were found to increase in a directly proportional manner compared with the mortality rates (12-15). In addition, factors such as the number of positive nodes, diameter of nodal metastasis, and lymph nodes capsule invasion also affect prognosis and recurrence rates $(3,12,16$, 17).

ALND is performed to determine adjuvant therapy, obtaining the right prognostic and staging information and ensure to control the disease in the axillary at a local level. ALND is recommended in patients with a high risk of recurrence, clinically palpable lymph nodes, or SLND positivity (18).

In current practice, there is a wide range of approaches for the evaluation of lymph nodes intraoperatively or permanently $(19,20)$. It is reported that lymph nodes should be scanned with 2-mm thick sections to identify metastases; however, however, it has also been found that in the examination of the nodal tissue with standard pathological techniques, metastases are overlooked $40 \%$ of cases. Moreover, it is observed that death occurs within 15 years due to metastatic breast carcinoma in $20 \%$ of patients with node-negative tumors (12). It is probable that the mortality rates 
observed in patients with node-negative tumors are associated with the metastases that were overlooked.

It was previously stated that for patients who underwent ALND, the number of dissected axillary lymph nodes should at least be 10 and that the samples should be taken from at least two axillary levels $(18,21,22)$. Michaelson et al. reported that the 15-year mortality rates in patients with 1-4 positive lymph nodes were $26 \%, 34 \%, 37 \%$, and 57\%, respectively (12). Previous studies showed that there is a direct correlation between the increase in the number of lymph nodes retrieved and the increase in the number of metastatic lymph nodes $(18,23)$. These results demonstrate the importance of the number of lymph nodes removed from axillary tissue.

The dissection of axillary material using the classical method basically relies on palpation and visualization. From time to time in routine practice, lymph nodes - primarily the small sized ones - may not be identified in dissection materials rich in fat tissue. Several studies have been performed on the easier visualization of lymph nodes by completely clearing the fat tissue (the clearing method) using chemicals such as ethanol, xylene, and acetone (24-26). Koren et al., aimed at the lymph nodes instead of the fat tissue by using LNRS, which is composed of chemicals such as glacial acetic acid, chloroform, diethyl ether, ethanol, formalin, and water. As a result, this made it easier to visualize and remove the lymph nodes by making them firmer and giving them a chalklike white color compared with that obtained using formalin fixation. (10, 26-28). Using both the clearing method and LNRS method increased the number of lymph nodes that could be removed $(10,25)$. In this study, the total number of lymph nodes increased in accordance with the literature. Micrometastatic nodal involvement comprises $15 \%$ of all patients with node positive tumors (29). Although pN1mi is equivalent to N0 according to the guidelines of the Current National Comprehensive Cancer Network, recent studies reported that patients with $\mathrm{pN} 1 \mathrm{mi}$ had a poorer prognosis compared with patients with $\mathrm{N} 0$, which was statistically significant, and that there was an average 3\% decrease in their 10-year survival rates compared with patients with node-negative tumors (30-34). Both the increase in the number of removed lymph nodes and the detection of smaller lymph nodes will facilitate the identification of micrometastases. As observed in this study, in addition to the increase in the number of lymph node retrieved using LNRS, smaller lymph nodes could be identified at each axillary level compared with that using the formalin solution.

Although Morrow et al. could not identify any patients who progressed to node-positive while they were node-negative using the clearing method, Koren et al. detected metastases that caused a change in the stage in patients with node-negative tumors using the LNRS method $(10,25)$. In our study, when retrieval was performed again with the LNRS method in patients with less than 10 lymph nodes detected with the formalin solution, the number of lymph nodes detected increased to 10. In this patient group, the total number of lymph nodes increased both in node-negative and node-positive cases. In addition to the stage progression in cases that became node-positive from node-negative, nodal stage progressions were also observed in patients with node-positive tumors as a result of the increase in the number of positive lymph nodes.

Similar results were obtained in studies done with LNRS on several dissection materials (27, 35, 36). Jan YJ et al. stated that LNRS could be preferred in lymph nodes dissection due to fast fixation and easier visualization of lymph nodes although there is no statistically significant difference 
(37). Similarly, even lymph nodes with a diameter of $1 \mathrm{~mm}$ could be easily detected using the LNRS method in our study.

Koren et al. reported in their studies that 12-hours time is adequate for the most suitable fixation (10). Similarly in our study, no difference was observed between the number and diameter of lymph nodes found through LNRS fixation in the 6-, 9-, and 12-hour groups. As a result, a 6-hour LNRS fixation time is adequate.

In conclusion, LNRS increases the number of retrievable lymph nodes and detects smaller-sized lymph nodes. Moreover, it is a low-cost solution that can be easily prepared with little experience using chemicals that are routinely used in pathology laboratories, and it is a valuable method in that a minimum 6 hours of fixation is sufficient. As observed in this study, a progression was in the nodal stage was observed after using LNRS. It is possible to select and remove higher number and smaller-sized lymph nodes with greater ease, especially in materials such as axillary or mesocolic fatty tissue, which are dense in fat tissue, in which the removal process is challenging in routine practice. It may be an alternative method in cases with removed lymph nodes are critical number or under. Thus, through the application of LNRS solution, it becomes possible to obtain more accurate nodal staging and prognostic information and ensure a more accurate treatment method.

Some data of the thesis study titled "The Evaluation of the Effect of Lymph Node Revealing Solution on Axillary Dissection Material" were used in this article.

\section{Acknowledgments}

We would like to thank Serdal Kenan Kose who performed statical analysis.

\section{References}

[1] Bray F, Ferlay J, Soerjomataram I, Siegel RL, Torre LA, Jemal A. Global cancer statistics 2018: GLOBOCAN estimates of incidence and mortality worldwide for 36 cancers in 185 countries. CA Cancer J Clin. 2018; 68:394-424. doi: 10.3322/caac.21492.

[2] Allred DC. Issues and updates: evaluating estrogen receptor-alpha, progesterone receptor, and HER2 in breast cancer. Mod Pathol. 2010;23 Suppl 2:S52-9. doi: 10.1038/modpathol.2010.55.

[3] Early Breast Cancer Trialists' Collaborative Group (EBCTCG). Effects of chemotherapy and hormonal therapy for early breast cancer on recurrence and 15-year survival: an overview of the randomised trials. Lancet. 2005;365(9472):1687-717.

[4] Stankov A, Bargallo-Rocha JE, Silvio AÑ, Ramirez MT, Stankova-Ninova K, Meneses-Garcia A. Prognostic factors and recurrence in breast cancer: experience at the national cancer institute of Mexico. ISRN Oncol. 2012; 2012:825258. doi: 10.5402/2012/825258.

[5] Pantel K, Brakenhoff RH. Dissecting the metastatic cascade. Nat Rev Cancer. 2004; 4:448-56.

[6] Wiechmann L, Sampson M, Stempel M, Jacks LM, Patil SM, King T, Morrow M. Presenting features of breast cancer differ by molecular subtype. Ann Surg Oncol. 2009; 16:2705-10. doi: 10.1245/s10434-009-0606-2.

[7] Giuliano AE, Connolly JL, Edge SB, Mittendorf EA, Rugo HS, Solin LJ, Weaver DL, Winchester DJ, Hortobagyi GN. Breast Cancer-Major changes in the American Joint Committee on Cancer eighth edition cancer staging manual. CA Cancer J Clin. 2017; 67:290-303. doi: 10.3322/caac. 21393 . 
[8] Vinh-Hung V, Cserni G, Burzykowski T, van de Steene J, Voordeckers M, Storme G. Effect of the number of uninvolved nodes on survival in early breast cancer. Oncol Rep. 2003; 10:363-8.

[9] Fisher ER, Costantino J, Fisher B, Redmond C. Pathologic findings from the National Surgical Adjuvant Breast Project (Protocol 4). Discriminants for 15-year survival. National Surgical Adjuvant Breast and Bowel Project Investigators. Cancer. 1993;71(6 Suppl):2141-50.

[10] Koren R1, Kyzer S, Paz A, Veltman V, Klein B, Gal R. Lymph Node Revealing Solution: A New Method for Detection of Minute Axillary Lymph Nodes in Breast Cancer Specimens. Am J Surg Pathol. 1997; 21:1387-90.

[11] Ghoncheh M, Pournamdar Z, Salehiniya H. Incidence and Mortality and Epidemiology of Breast Cancer in the World. Asian Pac J Cancer Prev. 2016; 17:43-6.

[12] Michaelson JS, Silverstein M, Sgroi D, Cheongsiatmoy JA, Taghian A, Powell S, Hughes K, Comegno A, Tanabe KK, Smith B. The effect of tumor size and lymph node status on breast carcinoma lethality. Cancer. 2003; 98:2133-43.

[13] Vinh-Hung V, Burzykowski T, Cserni G, Voordeckers M, Van De Steene J, Storme G. Functional form of the effect of the numbers of axillary nodes on survival in early breast cancer. Int J Oncol. 2003;22:697-704.

[14] Haffty BG, Ward B, Pathare P, Salem R, McKhann C, Beinfield M, Fischer D, Reiss M. Reappraisal of the Role of Axillary Lymph Node Dissection in the Conservative Treatment of Breast Cancer. J Clin Oncol. 1997;15:691-700.

[15] Valagussa P, Bonadonna G, Veronesi U. Patterns of relapse and survival following radical mastectomy. Analysis of 716 consecutive patients. Cancer. 1978; 41:1170-78.

[16] Ponzone R, Maggiorotto F, Mariani L, Jacomuzzi ME, Magistris A, Mininanni P, Biglia N, Sismondi P. Comparison of two models for the prediction of nonsentinel node metastases in breast cancer. Am J Surg. 2007; 193:686-92.

[17] Gurleyik G, Aker F, Aktekin A, Saglam A. Tumor characteristics influencing non-sentinel lymph node involvement in clinically node negative patients with breast cancer. J Breast Cancer. 2011;14:124-8. doi: 10.4048/jbc.2011.14.2.124.

[18] Somner JE, Dixon JM, Thomas JS. Node retrieval in axillary lymph node dissections: recommendations for minimum numbers to be confident about node negative status. J Clin Pathol. 2004 Aug;57(8):845-8.

[19] Cserni G. Pathological evaluation of sentinel lymph nodes. Surg Oncol Clin N Am. 2007;16:1734.

[20] Weaver DL, Le UP, Dupuis SL, Weaver KA, Harlow SP, Ashikaga T, Krag DN. Metastasis detection in sentinel lymph nodes: comparison of a limited widely spaced (NSABP protocol B-32) and a comprehensive narrowly spaced paraffin block sectioning strategy. Am J Surg Pathol. 2009;33:1583-9. doi: 10.1097/PAS.0b013e3181b274e7.

[21] Fisher B, Redmond C, Fisher ER, Bauer M, Wolmark N, Wickerham DL, Deutsch M, Montague E, Margolese R, Foster R. Ten-year results of a randomized clinical trial comparing radical mastectomy and total mastectomy with or without radiation. N Engl J Med. 1985;312:674-81.

[22] Grabau DA, Jensen MB, Blichert-Toft M, Andersen JA, Dyreborg U, Carstensen B, Al-Suliman NN, Graversen HP, Rose C. The importance of surgery and accurate axillary staging for survival in breast cancer. Eur J Surg Oncol. 1998 Dec;24(6):499-507.

[23] Fisher B, Wolmark N, Bauer M, Redmond C, Gebhardt M. The accuracy of clinical nodal staging and of limited axillary dissection as a determinant of histologic nodal status in carcinoma of the breast. Surg Gynecol Obstet. 1981;152:765-72.

[24] Durkin K, Haagemen CD. An improved technique for the study of lymph nodes in surgical specimen. Ann Surg1980;191:419-429.

[25] Morrow M, Evans J, Rosen PP, Kinne DW. Does clearing of axillary lymph nodes contribute to accurate staging of breast carcinoma? Cancer.1984;53:1329-1332. 
[26] Hartveit F, Samsonsen G, Tangen M, Halvorsen JF. Routine histological investigation of the axillary nodes in breast cancer. Clin Oncol. 1982;8:121-6.

[27] Horne J, Bateman AC, Carr NJ, Ryder I. Lymph node revealing solutions in colorectal cancer: should they be used routinely? J Clin Pathol. 2014;67:383-8. doi: 10.1136/jclinpath-2013-202146.

[28] Dias AR, Pereira MA, Mello ES, Zilberstein B, Cecconello I, Ribeiro Junior U. Carnoy's solution increases the number of examined lymph nodes following gastrectomy for adenocarcinoma: a randomized trial. Gastric Cancer. 2016;19:136-42. doi: 10.1007/s10120-014-0443-2.

[29] Peethambaram PP, Hoskin TL, Day CN, Goetz MP, Habermann EB, Boughey JC. Use of 21-gene recurrence score assay to individualize adjuvant chemotherapy recommendations in ER+/HER2node positive breast cancer-A National Cancer Database study. NPJ Breast Cancer. 2017;3:41.

[30] Grabau D, Jensen MB, Rank F, Blichert-Toft M. Axillary lymph node micrometastases in invasive breast cancer: national figures on incidence and overall survival. APMIS. 2007;115:828-37.

[31] Donald L Weaver. Pathology evaluation of sentinel lymph nodes in breast cancer: protocol recommendations and rationale. Modern Pathology volume23, pagesS26-S32 (2010).

[32] NCCN clinical Practice guidelines in oncology V.2.2018. Breast Cancer. (2018) Available online at: https://www.nccn.org/professionals/physician_gls/pdf/breast.pdf [Access OCT 21, 2018].

[33] Andersson Y, Bergkvist L, Frisell J, de Boniface J. Long-term breast cancer survival in relation to the metastatic tumor burden in axillary lymph nodes. Breast Cancer Res Treat. 2018;171:359-69.

[34] Iqbal J, Ginsburg O, Giannakeas V, Rochon PA, Semple JL, Narod SA. The impact of nodal micrometastasis on mortality among women with early-stage breast cancer. Breast Cancer Res Treat. 2017;161:103-15.

[35] Koren R, Paz A, Lask D, Kyzer S, Klein B, Schwartz A, Gal R. Lymph-node revealing solution: a new method for detecting minute lymph nodes in cystectomy specimens. Br J Urol. 1997 Jul;80:403.

[36] Koren R, Shvero J, Yaniv E, Veltman V, Konichezky M, Groushko I, Sadov R, Feinmesser R, Gal R. Neck-dissection surgical specimens treated by lymph node revealing solution. Otolaryngol Head Neck Surg. 2001;124:72-5.

[37] Jan YJ, Huang PC, Chen JT, Ho WL. Lymph node revealing solution and traditional 10\% buffered formaldehyde for detecting lymph nodes in colorectal carcinoma. Zhonghua Yi Xue Za Zhi (Taipei). 2000;63:131-7.

\footnotetext{
*Corresponding author.

E-mail address: tangul07@yahoo.com
} 